\title{
Are Density-dependent Effects on Elasmobranch Maturity Possible?
}

\author{
Katherine A. Sosebee \\ National Marine Fisheries Service, NEFSC \\ Woods Hole, MA 02543, USA
}

Sosebee, K. A. 2005. Are Density-dependent Effects on Elasmobranch Maturity Possible? J. Northw. Atl. Fish. Sci., 35: 115-124. doi:10.2960/J.v35.m492

\begin{abstract}
Fecundity and size at first maturity of elasmobranchs are believed to be limited by body size, making density-dependent effects on these life history traits unlikely. To examine the potential for density-dependent effects on size at first maturity, female spiny dogfish (Squalus acanthias) off the northeast coast of the United States were examined to determine both the presence of free embryos, fertilized eggs, or ovarian eggs, and the number of free embryos in each female in relation to maternal body size during 1998-2002. Severe biomass declines of the adult female portion of the population preceded and continued throughout the study period. Since the period of high abundance in the late$1980 \mathrm{~s}$, size at first maturity has declined from $75 \mathrm{~cm}$ to $66 \mathrm{~cm}$ and the median size at maturity $\left(L_{50}\right)$ has declined from $85 \mathrm{~cm}$ to $79 \mathrm{~cm}$; however, the relationship between number of free embryos and maternal length has not changed.
\end{abstract}

Key words: density, maturity, size, egg, embryo, dogfish, abundance.

\section{Introduction}

Spiny dogfish (Squalus acanthias) are distributed on both sides of the Atlantic Ocean as well as in the Pacific Ocean (Burgess, 2002). Distribution in the Northwest Atlantic extends from Newfoundland to North Carolina and spiny dogfish in this area are considered to represent a single unit population (NEFSC, 1994). The biology of the species has been studied for more than 50 years in all areas where dogfish are found (Kaganovskaia, 1933; Holden and Meadows, 1964; Jensen, 1966; Ketchen, 1972; Ketchen, 1975; Jones and Geen, 1977; Nammack, 1982; Nammack et al., 1985; McFarlane and Beamish, 1987). The last study on reproduction of spiny dogfish in the Northwest Atlantic was conducted in the late-1980s (Silva, 1993). At that time, the biomass of the stock was increasing from low levels in the 1970s (NEFSC, 1998; Rago et al., 1998). A stock assessment conducted in 1997 determined that the biomass of large females $(>80 \mathrm{~cm})$ was $50 \%$ of the 1989 peak (NEFSC, 1998).

Owing to the large size free embryos relative to adult length, life history theory of dogfish has suggested a limited capability for density-dependent effects on fecundity and maturity (Holden, 1973). Holden (1973) suggested that density-dependent effects on fecundity were more likely because these effects contributed more to lifetime fecundity than density-dependent effects on size at first maturity or size at $50 \%$ maturity. A comparison of the highly exploited Scottish-Norwegian stock of spiny dogfish to the lightly exploited Newfoundland stock suggested an increase in fecundity with lower abundance (Templeman, 1944; Holden and Meadows, 1962). Studies of dogfish stocks from the waters of British Columbia showed little change in fecundity in relation to abundance (Bonham et al., 1949; Ketchen, 1972; Jones and Geen, 1977). However, most of the exploitation had occurred prior to any of the studies. Silva (1993) demonstrated for the Northwest Atlantic stock that decreases in fecundity at size occurred with increases in abundance. Holden (1973) also suggested that size at maturity is invariant while age at maturity will depend on growth rate. However, Silva (1993) demonstrated that total female length at 50\% maturity $\left(L_{50}\right)$ did increase with an increase in abundance. This paper presents the results of a study initiated in 1998 to estimate maturity and fecundity of spiny dogfish in the waters off the northeastern United States and southwestern Nova Scotia, and to determine if there have been any density-dependent changes associated with the decline in the abundance of mature females.

\section{Methods}

Spiny dogfish females $65 \mathrm{~cm}$ or greater in total length $(10 \mathrm{~cm}$ below the previously estimated size at first maturity) were examined during the bottom trawl surveys conducted by the Northeast Fisheries Science Center (NEFSC) from 1998-2002 (Fig. 1). The trawl surveys were conducted in three seasons: winter (February), spring 


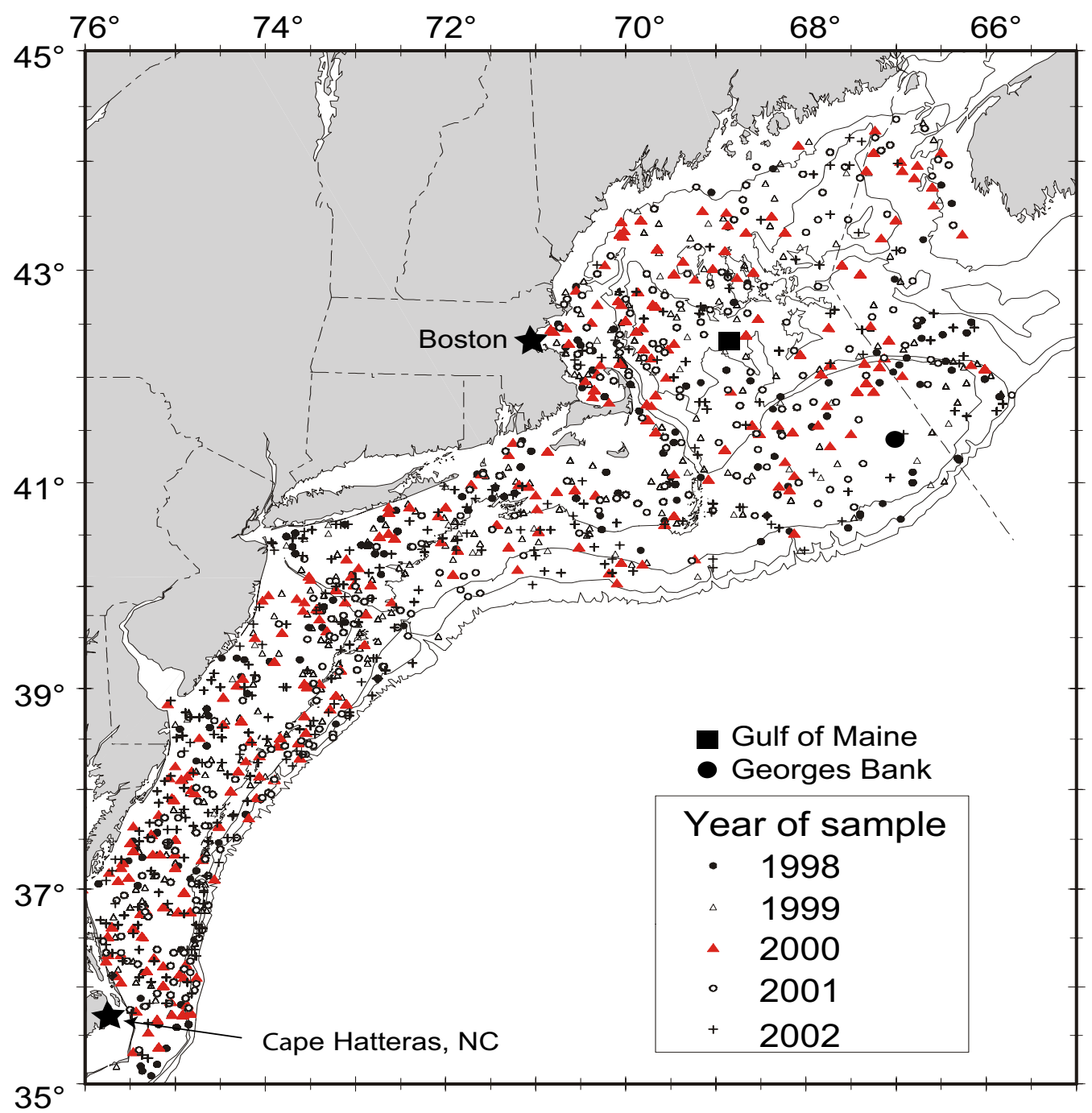

Fig. 1. Location of female spiny dogfish sampled for maturity during 1998-2002 by year, all seasons combined.

(March-April), and autumn (September-October) (Azarovitz, 1981). The spring and autumn surveys covered the region from Cape Hatteras through to the Gulf of Maine. The winter survey covered the region from Cape Hatteras to Georges Bank.

Each female was examined for the presence of free embryos, fertilized uterine eggs (candled embryos) and ovarian eggs. Immature females were classified as those with small ovaries containing either no eggs or small, non-developing eggs. A female was determined to be mature if large, well-developed eggs were present in the ovaries or if embryos were present in the uterus. If free embryos were present and time permitted, the embryos were counted for fecundity analysis. Candled embryos and ovarian eggs were not used in the fecundity analyses because they were prone to rupture.

\section{Maturity Analysis}

The proportions of mature females at 1-cm length intervals were determined for each year. A logistic model (Dixon, 1985) was fit to the data by using the probit procedure:

$$
P=\frac{1}{1+e^{-(\alpha+\beta \times)}}
$$

where $P \quad$ is the proportion mature at length,

$x \quad$ is the total length in $\mathrm{cm}$,

$a, b \quad$ is the parameters to be estimated.

Model fits were subjected to $\chi^{2}$ goodness-of- fit tests. Approximate $95 \%$ confidence limits were estimated by 
using the SAS probit procedure (SAS, 1995). Linear regressions were used to compare the abundance of females $\geq 65 \mathrm{~cm}$ collected during the NEFSC spring bottom trawl surveys to correspond with the sizes used in the maturity analysis, and a linear regression was performed. A three-year moving average was used for the abundance of females because the survey estimates exhibit high variability (NEFSC, 1998).

\section{Fecundity Analysis}

Fecundity estimates used the counts of free embryos following the methods of Silva (1993). The mean and standard deviation by $5 \mathrm{~cm}$ size-classes were calculated for each year. Overall means by size-class and year were also calculated. A weighted mean was calculated by using the three-year moving average of female abundance from the NESFC spring survey as the weighting factor to determine the average number of free embryos per female in the population. A three-year moving average was used for the abundance of females because the survey estimates exhibit high variability (NEFSC, 1998). Analysis of covariance was performed on log-transformed length and numbers of free embryos to determine if there was a difference in slope by year.

\section{Results}

Of the 7481 females examined throughout the study, 1290 contained free embryos (Table 1). Examined females were collected throughout the US waters of the Northwest Atlantic, with the distribution of collections remaining similar in all years of the study (Fig. 1).

\section{Maturity Analysis}

The estimated length at 50\% maturity declined from $82.2 \mathrm{~cm}$ in 1998 to $79.1 \mathrm{~cm}$ in 2002 (Table 2). All logistic regressions fit the data well $(P>0.05)$. The regressions by year with the raw data illustrate the change in $L_{50}$ over time (Fig. 2). The decline in $L_{50}$ was significant with the confidence limits for 1998 and 1999 not overlapping those for 2000-2002. The relationship between $L_{50}$ and abundance, however, was weak and non-significant $\left(r^{2}=\right.$ $0.25, P=0.18$ ) (Fig. 3).

\section{Fecundity Analysis}

Free embryos were found in females in all seasons and most areas (Fig. 4). However, concentrations appeared in the Mid-Atlantic and in the inshore waters of Cape Cod Bay that persisted over time.

The smallest female containing free embryos, was $66 \mathrm{~cm}$. The mean number of free embryos per female increased three-fold from the smallest length interval $(65-69 \mathrm{~cm})$ to the largest interval $(105-109 \mathrm{~cm})$ (Table 3). Analysis of covariance revealed that there was no significant difference in slopes among years (Fig. $5 ; P=0.2113$ ). The overall mean number of free embryos per female was 4.4 with the yearly means ranging from 4.6 in 1998 to 4.3 in 1999. The weighted means varied from 2.0 (2000) to 3.6 (1999) during the time of the study.

\section{Discussion}

The size at first maturity declined from $75 \mathrm{~cm}$ in the late-1980s to $66 \mathrm{~cm}$ in the late-1990s. This may be related to the reduction in mature female biomass that occurred over the last decade. The change in $L_{50}$ is also related to the declining abundance of reproductive females in the population. The relationship between female abundance and $L_{50}$, although weak, does indicate that there may be some density-dependent changes occurring. If the 1985-86 data point is considered an outlier and removed from the analysis, the significance of the regression is

TABLE 1. Number of female spiny dogfish examined by year and season $(\mathrm{T}=$ total number examined, $\mathrm{FE}=$ Number with free embryos).

\begin{tabular}{|c|c|c|c|c|c|c|c|}
\hline & & 1998 & 1999 & 2000 & 2001 & 2002 & Total \\
\hline \multirow[t]{2}{*}{ Winter } & $\mathrm{T}$ & 246 & 552 & 497 & 726 & 301 & 2322 \\
\hline & FE & 59 & 132 & 84 & 110 & 42 & 427 \\
\hline \multirow[t]{2}{*}{ Spring } & $\mathrm{T}$ & 283 & 926 & 786 & 582 & 557 & 3134 \\
\hline & FE & 60 & 167 & 96 & 69 & 70 & 462 \\
\hline \multirow[t]{2}{*}{ Autumn } & $\mathrm{T}$ & 391 & 505 & 416 & 713 & & 2025 \\
\hline & FE & 115 & 162 & 51 & 73 & & 401 \\
\hline \multirow[t]{2}{*}{ Total } & $\mathrm{T}$ & 920 & 1983 & 1699 & 2021 & 858 & 7481 \\
\hline & $\mathrm{FE}$ & 234 & 461 & 231 & 252 & 112 & 1290 \\
\hline
\end{tabular}


TABLE 2. Parameter estimates ( $\alpha$ and $\beta$ ) associated with the logistic regression of female spiny dogfish maturity data collected from 1998-2002. The degrees of freedom (DF, number of length intervals), goodness-of-fit $\left(P>\chi^{2}\right)$ and $L_{50}$ are also given.

\begin{tabular}{lrrrrr}
\hline \hline Parameters & 1998 & 1999 & 2000 & 2001 & 2002 \\
\hline$\alpha$ & -26.4 & -29.2 & -27.7 & -26.2 & -25.5 \\
$S E_{\alpha}$ & 1.71 & 1.29 & 1.33 & 1.15 & 1.70 \\
$\beta$ & 0.321 & 0.363 & 0.349 & 0.330 & 0.322 \\
$S E_{\beta}$ & 0.0210 & 0.0162 & 0.0168 & 0.0147 & 0.0216 \\
$D F$ & 39 & 35 & 35 & 36 & 37 \\
$P>\chi^{2}$ & 0.7565 & 0.8767 & 0.8656 & 0.9739 & 1.0000 \\
$L_{50}$ & 82.2 & 80.5 & 79.3 & 79.4 & 79.1 \\
\hline
\end{tabular}

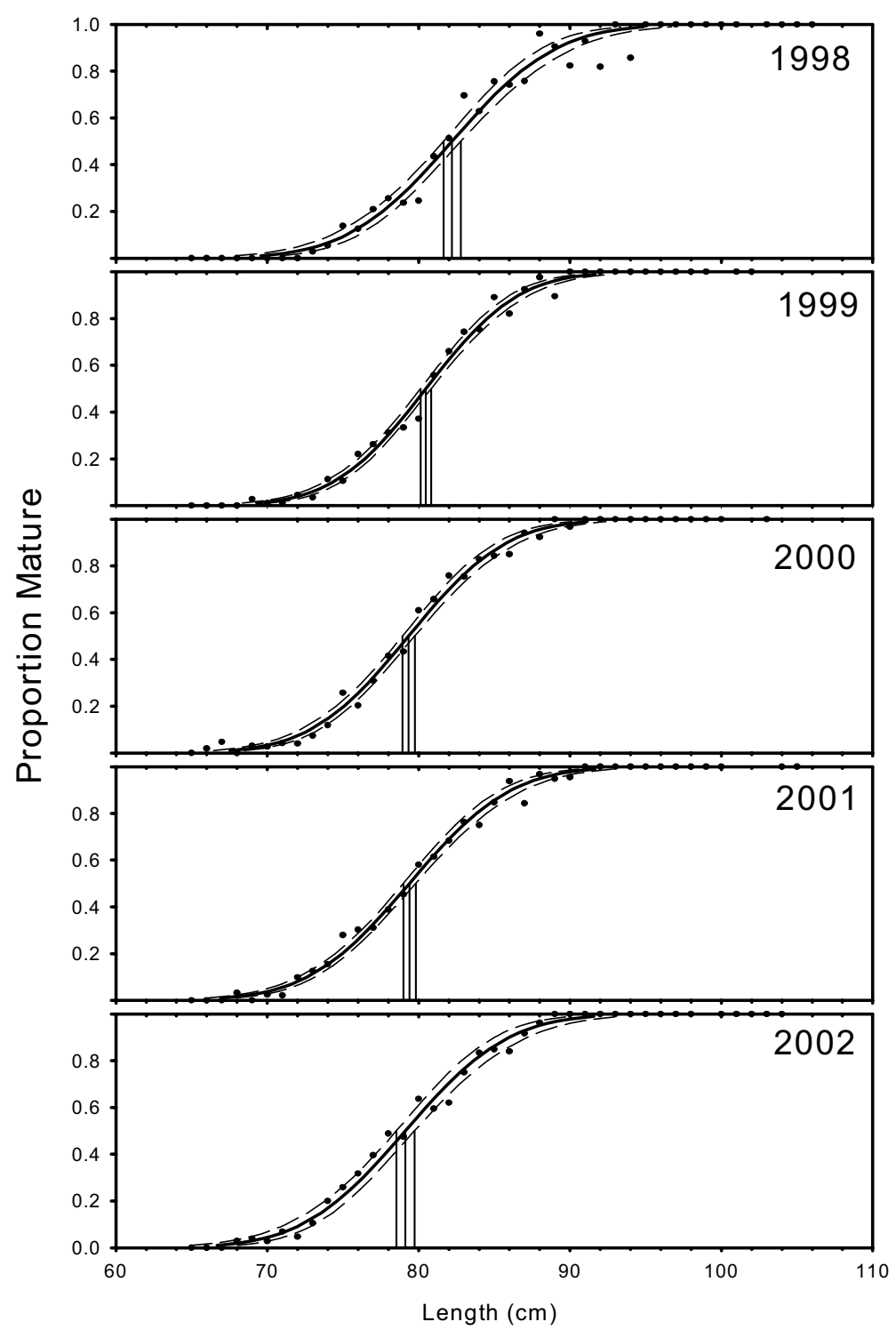

Fig. 2. Proportion of mature female spiny dogfish as a function of fish length with fitted logistic lines plotted by year. The dashed lines are approximate $95 \%$ confidence intervals. The vertical lines indicate the value of $L_{50}$ and its confidence limits. 


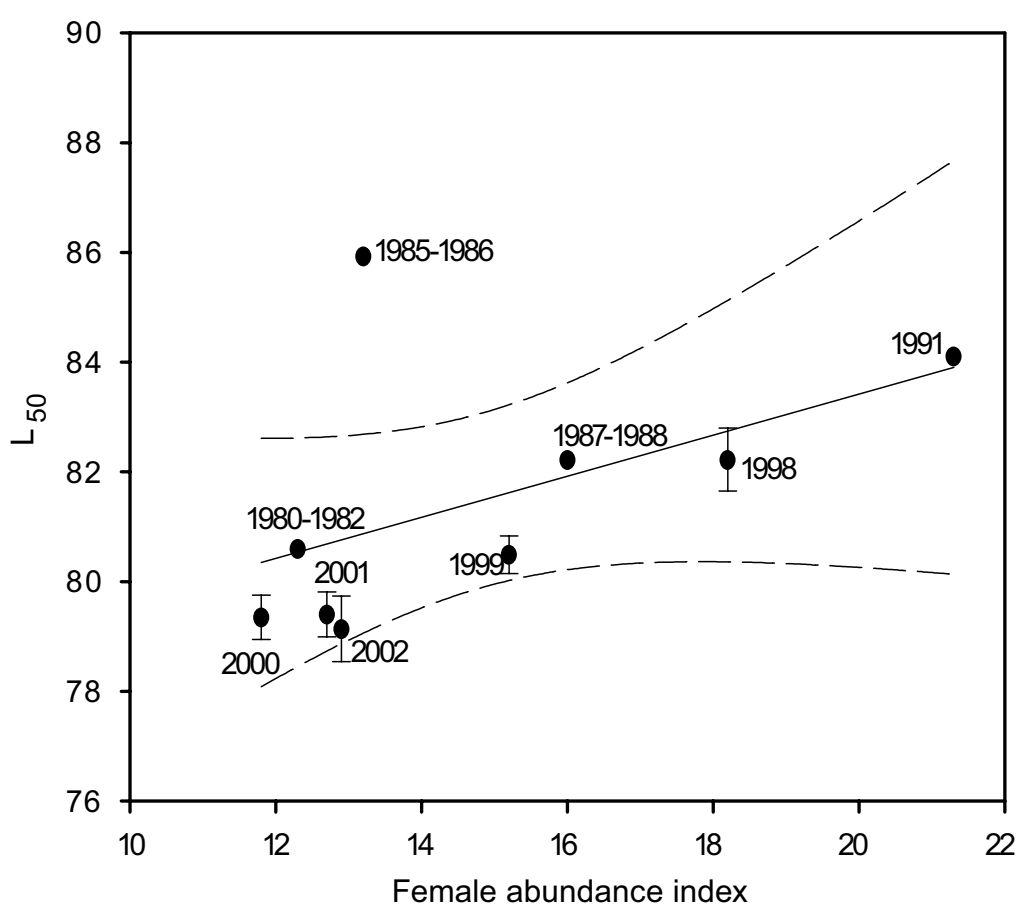

Fig. 3. $L_{50}$ regressed against three-year moving average of female abundance $\geq 65 \mathrm{~cm}$ from NEFSC spring survey. Data from 1980-82 are the recomputed estimates from Silva (1993) and the 1985-86, 1987-88 and 1991 dates are from Silva (1993).

greatly increased $\left(r^{2}=0.87, P<0.001\right)$. However, there is no statistical justification for removal of the data point at this time. It may be that as more years of data are collected, the relationship between $L_{50}$ and abundance will become stronger.

Silva (1993) found density-dependent changes occurring in the growth rates of juveniles and in the number of embryos by size. Silva (1993) concluded that these changes were responses to the increase in biomass that occurred in the 1980s. What appears to have occurred in my study is a return to the conditions of the late-1970s and early-1980s when $L_{50}$ was $80 \mathrm{~cm}$ (Nammack, 1982; Nammack et al., 1985). The reduction in $L_{50}$ appears to have halted in the last three years, possibly indicating that there is a lower limit to the size at which reproduction can occur in this species. However, the abundance of reproductive animals is no longer declining, so further density-dependent changes may have been halted.

The mean number of free embryos per female has been reduced from 6.6 (Nammack, 1982) to 4.4 (this study). The mean number of free embryos per female weighted by abundance has also declined from 5.3 (recomputed from Nammack, 1982) to a low of 2.0 in 2000. This is likely due to the truncation of the size structure in the population with fewer females greater than $85 \mathrm{~cm}$ (Fig. 6). There are few females large enough to contain more than 4 to 5 fully developed embryos (Fig. 6). In previous studies, examined females contained up to 16 embryos, but the largest number of embryos found in this study was 12 .

There does not appear to be evidence of densitydependent changes in fecundity occurring at this time. The number of free embryos per length grouping has not increased with female abundance. There was no evidence of change in the regression parameters of number of free embryos on maternal length. This could be a slower density-dependent change than that of size at maturity and has not yet been detected.

Based on my study density-dependent effects on spiny dogfish maturity are possible, but fecundity at length may be invariant. This is contradictory to the sug- 


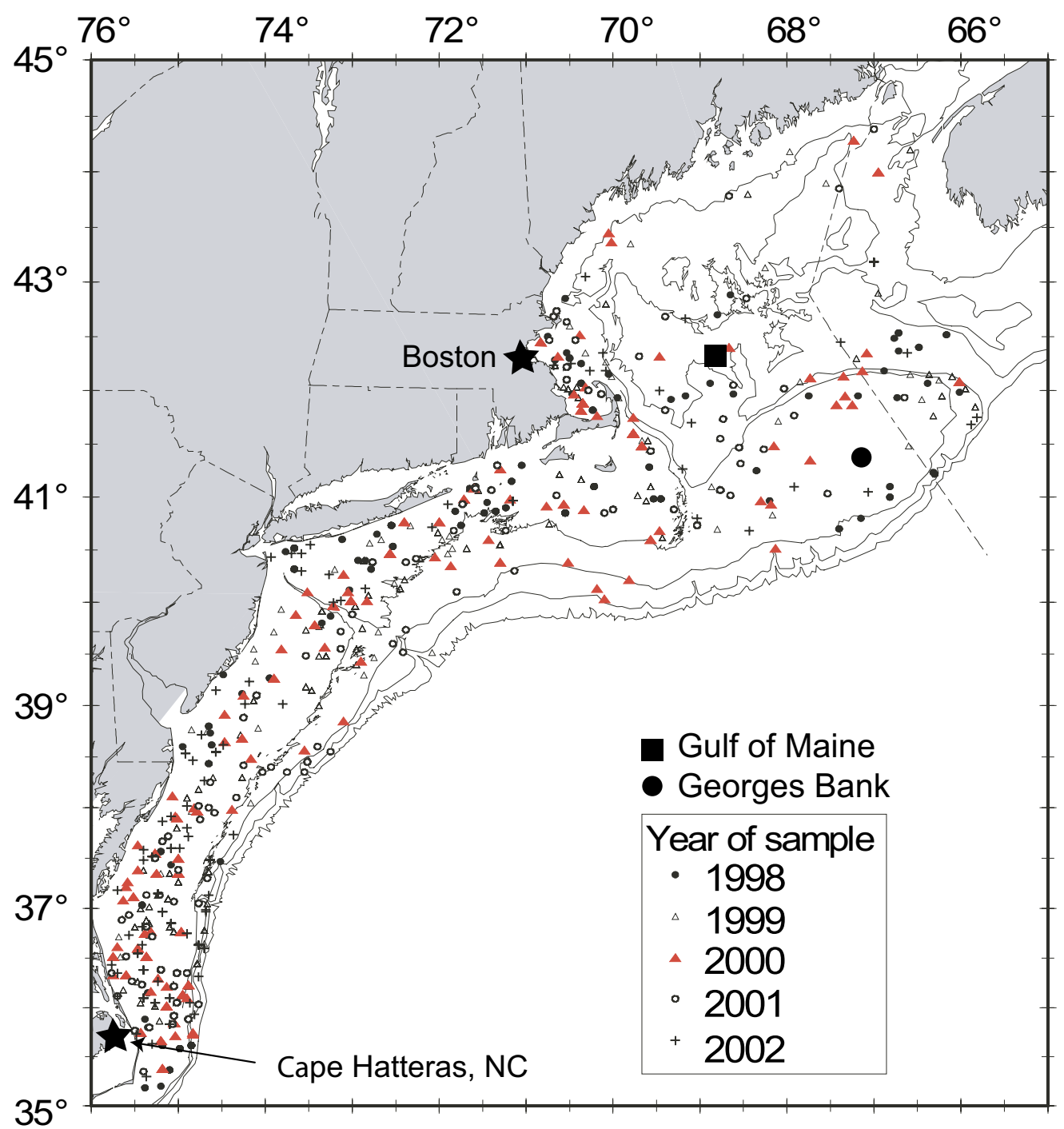

Fig. 4. Location of female spiny dogfish containing free embryos during 1998-2002 by year, all seasons combined

gestion made by Holden (1973). Changes in the growth rate of the population may not be occurring at this time. If the biomass of mature females continues to decline in this population, further density-dependent changes may be detected, but it is not clear how fast or to what extent they may continue to occur.

\section{Acknowledgements}

The author thanks P. Rago and R. Mayo for reviews of this manuscript. The author is also indebted to the many scientists and crew of the Albatross $I V$ who participated in the research cruises to collect the data. 
TABLE 3. Numbers of free embryos per female spiny dogfish at $5 \mathrm{~cm}$ size intervals. Sample means (top), standard deviations (middle), and sample sizes (bottom) are presented. The weighted mean and the range in number of free embryos are shown.

\begin{tabular}{|c|c|c|c|c|c|c|}
\hline \multirow{2}{*}{$\begin{array}{l}\text { Length-class } \\
\qquad(\mathrm{cm})\end{array}$} & \multicolumn{6}{|c|}{ Year } \\
\hline & 1998 & 1999 & 2000 & 2001 & 2002 & Average \\
\hline \multirow[t]{3}{*}{$65-69$} & & 2.00 & - & - & 3.00 & 2.50 \\
\hline & - & - & - & - & - & 0.71 \\
\hline & - & 1 & - & - & 1 & 2 \\
\hline \multirow[t]{3}{*}{$70-74$} & 3.00 & 4.67 & - & 3.00 & - & 4.25 \\
\hline & - & & 1.86 & - & - & 1.75 \\
\hline & 1 & 6 & - & 1 & - & 8 \\
\hline \multirow[t]{3}{*}{$75-79$} & 3.62 & 3.28 & 3.38 & 3.12 & 2.67 & 3.29 \\
\hline & 1.50 & 0.9 & 0.92 & 0.99 & 0.58 & 1.03 \\
\hline & 13 & 53 & 8 & 17 & 3 & 94 \\
\hline \multirow[t]{3}{*}{$80-84$} & 3.73 & 3.96 & 3.81 & 3.95 & 3.57 & 3.87 \\
\hline & 1.34 & 1.15 & 1.28 & 1.10 & 0.75 & 1.19 \\
\hline & 77 & 170 & 36 & 42 & 21 & 345 \\
\hline \multirow[t]{3}{*}{$85-89$} & 4.46 & 4.31 & 4.14 & 4.12 & 4.42 & 4.31 \\
\hline & 1.39 & 1.27 & 1.29 & 1.36 & 1.29 & 1.31 \\
\hline & 81 & 141 & 35 & 50 & 48 & 355 \\
\hline \multirow[t]{3}{*}{$90-94$} & 5.60 & 5.75 & 5.71 & 5.53 & 5.37 & 5.61 \\
\hline & 1.83 & 1.36 & 1.72 & 1.42 & 1.36 & 1.52 \\
\hline & 35 & 48 & 17 & 17 & 27 & 144 \\
\hline \multirow[t]{3}{*}{$95-99$} & 6.90 & 6.08 & 6.33 & 6.25 & 5.50 & 6.24 \\
\hline & 1.63 & 1.89 & 1.53 & 1.54 & 2.33 & 1.79 \\
\hline & 13 & 13 & 3 & 12 & 8 & 49 \\
\hline \multirow[t]{3}{*}{$100-104$} & 9.50 & 8.00 & - & 5.00 & 5.00 & 7.10 \\
\hline & 1.91 & - & - & - & 2.83 & 3.00 \\
\hline & 4 & 1 & - & 1 & 4 & 10 \\
\hline \multirow[t]{3}{*}{$105-109$} & 9.67 & - & - & - & - & 9.67 \\
\hline & 2.08 & - & - & - & - & 2.08 \\
\hline & 3 & - & - & - & - & 3 \\
\hline \multirow[t]{3}{*}{ All sizes } & 4.63 & 4.27 & 4.30 & 4.30 & 4.50 & 4.39 \\
\hline & 1.92 & 1.43 & 1.55 & 1.52 & 1.53 & 1.59 \\
\hline & 227 & 433 & 98 & 140 & 112 & 1010 \\
\hline Weighted mean & 3.07 & 3.65 & 2.00 & 2.87 & 2.52 & \\
\hline Range in No. & $1-12$ & $1-10$ & $1-9$ & $1-9$ & $1-9$ & \\
\hline
\end{tabular}




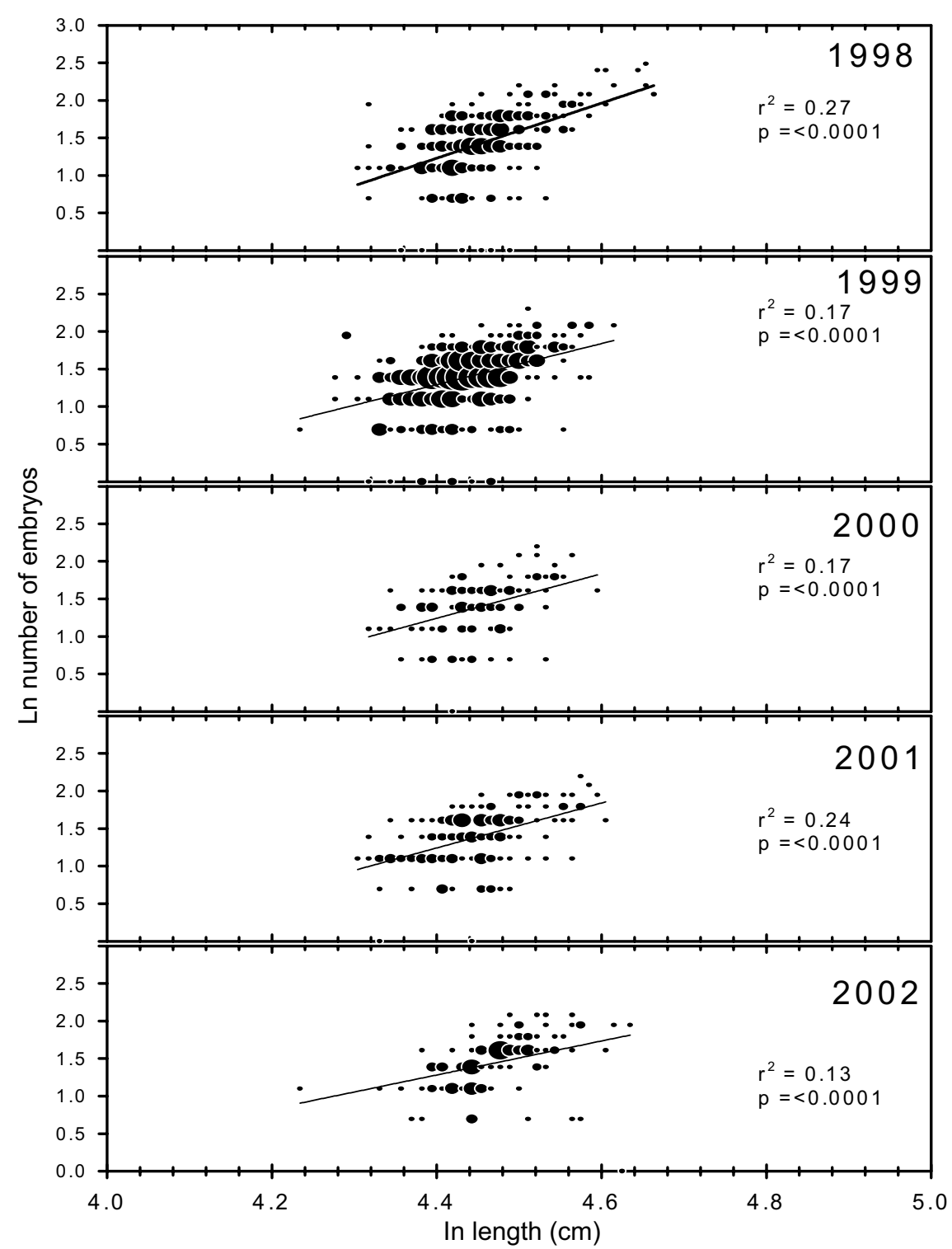

Fig. 5. Number of free embryos at length by year, all seasons combined on natural logarithm scale. The size of the dots are proportional to the number of observations. A linear regression is plotted for each year. 


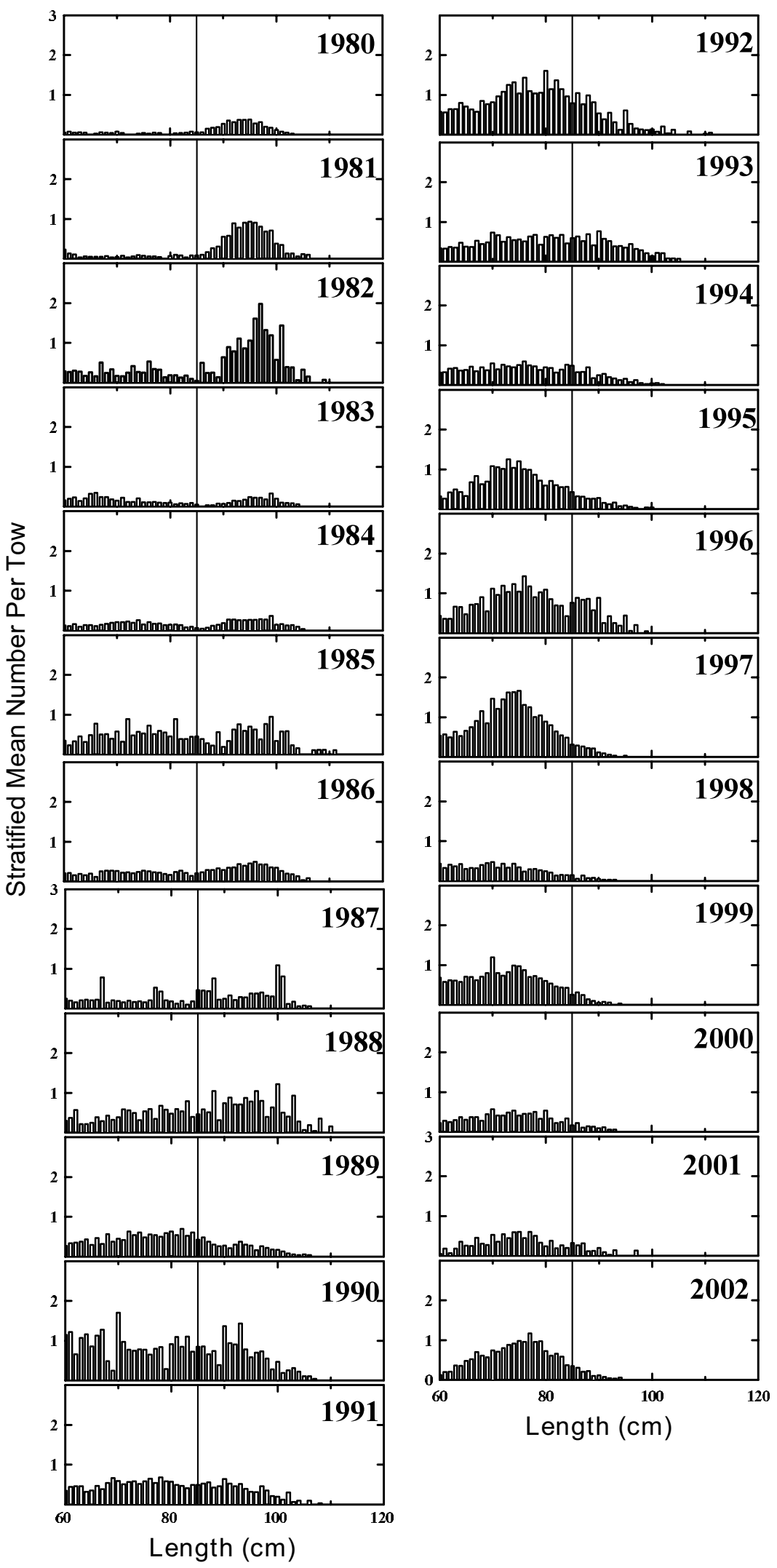

Fig. 6. Length frequency composition of female spiny dogfish $(>60 \mathrm{~cm})$ from NEFSC spring surveys, 1980-2002. The vertical line designates the location of the $85 \mathrm{~cm}$ length interval. 


\section{References}

AZAROVITZ, T. R. 1981. A brief historical review of the Woods Hole Laboratory trawl survey time series. In: Bottom trawl surveys. W. G. Doubleday, and D. Rivard (eds.). Can. Spec. Publ. Fish. Aquat. Sci., 58: 62-67.

BONHAM, K. F., F. B. SANFORD, W. CLEGG, and G. C. BUCKER. 1949. Biological and vitamin A studies of dogfish (Squalus acanthias) landed in the State of Washington. Wash. Dep. Fish. Biol. Rep., 49A: 83-114.

BURGESS, G. H. 2002. Spiny Dogfishes. Family Squalidae. In: Bigelow and Schroeder's fishes of the Gulf of Maine $3^{\text {rd }}$ ed., B. B. Collette, and G. Klein-MacPhee (eds.). Smithsonian Institution Press, p. 48-57.

DIXON, W. J. (ed.). 1985. BMDP Statistical Software. University of California Press, $725 \mathrm{p}$.

HOLDEN, M. J. 1973. Are long-term sustainable fisheries for elasmobranchs possible? In: Fish stocks and recruitment. ICES Rapp. Proc.-Verb., 164: 360-367.

HOLDEN, M. J., and P. S. MEADOWS. 1962. The structure of the spine of the spur dogfish (Squalus acanthias L.) and its use for age determination. J. Mar. Biol. Ass. U.K., 42: 179-197.

1964. The fecundity of the spurdog (Squalus acanthias L.). ICES Proc.-Verb., 28(3): 418-424.

JENSEN, A. C. 1966. Life history of the spiny dogfish. Fish. Bull., 65(3): 527-554.

JONES, B. C., and G. H. GEEN 1977. Reproduction and embryonic development of spiny dogfish (Squalus acanthias) in the Strait of Georgia, British Columbia. J. Fish. Res. Board Can., 34: 1286-1292.

KAGANOVSKAIA, S. M. 1933. A method of determining the age and catch composition of the spiny dogfish (Squalus acanthias L.). Vestn. Dal'nevost. Fil. Akad. Nauk SSSR., 1-3: 130-141 (Transl. from Russian by Fish. Res. Board Can., Transl. Ser., No. 281, 1960).

KETCHEN, K. S. 1972. Size at maturity, fecundity, and embryonic growth of the spiny dogfish (Squalus acanthias) in British Columbia waters. J. Fish. Res. Board Can., 29:
$1717-1723$

1975. Age and growth of dogfish, Squalus acanthias, in British Columbia waters. J. Fish. Res. Board Can., 32: 43-59.

MCFARLANE, G. A., and R. J. BEAMISH. 1987. Validation of the dorsal spine method of age determination for spiny dogfish. In: The age and growth of fish. R. C. Summerfelt and G. E. Hall (eds.). Iowa State University Press, Ames. p. 287-300.

NAMMACK, M. F. 1982. Life history and management of spiny dogfish (Squalus acanthias) off the Northeastern United States. MA Thesis. The College of William and Mary, Virginia, 63 p.

NAMMACK, M.F., J.A. MUSICK, and J.A. COLVOCORESSES. 1985. Life history of spiny dogfish off the Northeastern United States. Trans. Am. Fish. Soc., 114: 367-376.

NEFSC. 1994. Report of the $18^{\text {th }}$ Northeast Regional Stock Assessment Workshop: Stock Assessment Review Committee (SARC) Consensus Summary of Assessments. NOAA/NMFS/NEFSC: Woods Hole, MA. NEFSC Ref. Doc., No. 94-22.

1998. Report of the $26^{\text {th }}$ Northeast Regional Stock Assessment Workshop: Stock Assessment Review Committee (SARC) Consensus Summary of Assessments. NOAA/NMFS/NEFSC: Woods Hole, MA. NEFSC Ref. Doc., No. 98-04.

RAGO, P. J., K. A. SOSEBEE, J. K. T. BRODZIAK, S. A. MURAWSKI, and E. D. ANDERSON. 1998. Implications of recent increases in catches on the dynamics of Northwest Atlantic spiny dogfish (Squalus acanthias). Fish. Res., 39: 165-181.

SAS Institute Inc. 1995. Logistic regression Examples Using the SAS System, Version 6, First Edition. Cary, N. C., SAS Institute Inc., $163 \mathrm{p}$.

SILVA, H. M. 1993. Population dynamics of spiny dogfish, Squalus acanthias, in the NW Atlantic. Amherst, MA. University of Massachusetts. Dissertation.

TEMPLEMAN, W. 1944. The life history of the spiny dogfish, (Squalus acanthias) and the vitamin A values of dogfish liver oil. Res. Bull. Dev. Fish. Resour. Nfld., 15: 102 p. 